\title{
Left Recurrent Laryngeal Nerve Palsy Secondary to Left Pulmonary Artery Stent in a Child
}

\author{
Daisuke Kobayashi, ${ }^{\star}$ MD, Daniel R. Turner, MD, and Richard A. Humes, MD

\begin{abstract}
We report a 10-year-old girl who developed persistent hoarseness after stent placement for the treatment of left pulmonary artery stenosis. Laryngoscopy performed 21 months after stent placement revealed left vocal cord paralysis, presumed secondary to compression of the left recurrent laryngeal nerve by the stent. Pediatric cardiologists should be reminded of this possible rare complication after stent placement. ๑ 2012 Wiley Periodicals, Inc.
\end{abstract}

Key words: hoarseness; stent; complication

\section{INTRODUCTION}

Stents may be used to relieve isolated pulmonary artery stenoses [1]. Left recurrent laryngeal nerve (LRLN) palsy secondary to pulmonary artery stent placement was not reported in a recent large cohort study [1]. Assaqqat et al. reported a 12-year-old girl who developed hoarseness after coil occlusion of the ductus arteriosus and left pulmonary artery (LPA) stent placement. In this patient, laryngoscopy confirmed paralysis of the LRLN [2]. We report a 10-year-old girl who developed LRLN palsy after isolated LPA stent placement.

\section{CASE REPORT}

The patient initially presented at 4 years of age for evaluation of heart murmur. Echocardiography demonstrated LPA stenosis with a mildly increased Doppler velocity of $2.2 \mathrm{~m}$ per sec. She was asymptomatic from the cardiovascular standpoint and was followed clinically with serial echocardiography. At 10 years of age, a lung perfusion scan using technetium-99m demonstrated globally decreased radiotracer activity in the left lung with a differential perfusion of $20 \%$ to the left lung and $80 \%$ to the right lung. Cardiac MRI demonstrated significant proximal LPA stenosis with a diameter of $6 \mathrm{~mm}$ compared to the right pulmonary artery diameter of $13.7 \mathrm{~mm}$ (Fig. 1). Cardiac catheterization revealed a gradient of $12 \mathrm{mmHg}$ from the main pulmonary artery to the LPA. The systolic pressure of right ventricle was $29 \mathrm{mmHg}$ with no gradient to the main pulmonary artery. Angiography further delineated the proximal LPA stenosis, measuring $6.7 \mathrm{~mm}$ in the lateral projection (Fig. 2A). The distal LPA measured $14 \mathrm{~mm}$. Stent placement was performed using a Genesis- $\mathrm{XD}^{\circledR} 29 \mathrm{~mm}$ length stent delivered on a $15 \mathrm{~mm} \times$ $3 \mathrm{~cm}$ Braun Z-med II ${ }^{\circledR}$ balloon, resulting in complete relief of the gradient from the main pulmonary artery to the LPA (Fig. 2B). Repeat lung perfusion scan was normal with $45 \%$ flow to the left lung and $55 \%$ to the right lung. Echocardiography showed no evidence of residual stenosis. The patient developed hoarseness after the procedure, thought secondary to LRLN compression by the LPA stent. Her hoarseness did not resolve. Laryngoscopy performed 21 months after stent placement demonstrated left vocal cord paralysis.

\section{DISCUSSION}

The LRLN originates from the vagus nerve and loops under the aortic arch, posterior to the ligamentum arteriosus and superior to the LPA. Injury to the LRLN has been reported with both surgical ligation and transcatheter occlusion of patent ductus arteriosus (PDA) [3,4]. Javois et al. reported a retrospective study of 200 patients after transcatheter PDA occlusion [4]. LPA stenosis prior to PDA occlusion was present $5 \%$ of the time and was suspected to be related to insertion of ductal tissue around the orifice of the LPA [4]. Left recurrent

Division of Pediatric Cardiology, Carman and Ann Adams Department of Pediatrics, Children's Hospital of Michigan, Wayne State University School of Medicine, Detroit, Michigan

Conflict of interest: Nothing to report.

*Correspondence to: Daisuke Kobayashi, Division of Pediatric Cardiology, Carman and Ann Adams Department of Pediatrics, Children's Hospital of Michigan, Wayne State University School of Medicine, 3901 Beaubien Blvd, Detroit, MI 48201-2119.

E-mail: dkobayas@dmc.org

Received 18 July 2011; Revision accepted 31 October 2011

DOI 10.1002/ccd.23472

Published online 15 March 2012 in Wiley Online Library (wileyonlinelibrary.com) 


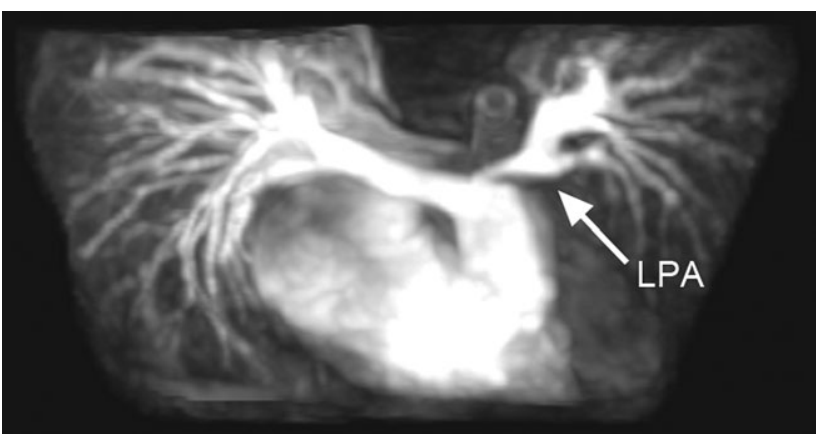

Fig. 1. Cardiac MRI. Cranial view of 3D reconstruction image demonstrated the severe stenosis of proximal left pulmonary artery (LPA).

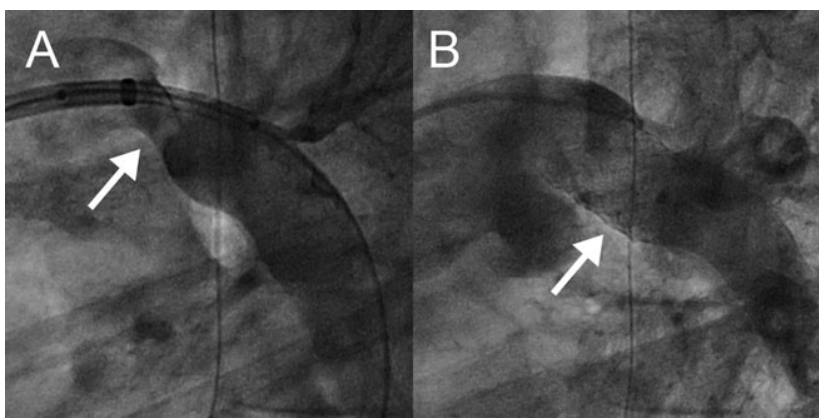

Fig. 2. Lateral projection of angiography, demonstrating the left pulmonary artery (LPA). (A) There was significant stenosis (arrow) in the proximal LPA before the stent placement; (B) The stent (arrow) was successfully placed on the proximal LPA.

laryngeal nerve paralysis was an uncommon complication $(0.5 \%)$, but appeared to be associated with marked foreshortening of the long, type E, PDA [4]. Poteliakhoff et al. reported LRLN paralysis due to dilation of the pulmonary artery in a case of bronchitis and asthma [5]. The LRLN can be compressed between the pulmonary artery and the aortic arch while being held in place by the ligamentum arteriosum [5]. We speculate that isolated proximal LPA stenosis may be caused by migrated ductal tissue and a tense ligamentum arteriosus. Thus, stent placement in isolated proximal LPA can compress the LRLN by the same mechanism described above (Fig. 3).

The indication for intervention in significant branch pulmonary artery stenosis is defined by a recent American Heart Association guideline [6]. Pulmonary angioplasty and stent placement are indicated for the treatment of significant peripheral branch pulmonary artery stenosis (class I indication). Significant stenosis is defined as (1) a measureable gradient of $>20-30 \mathrm{mmHg}$ across the stenosis area, when there is elevation of the right ventricle or proximal main pulmonary artery pressure to greater than one-half to two-thirds of systemic pressure secondary to the more distal obstruction, or (2)

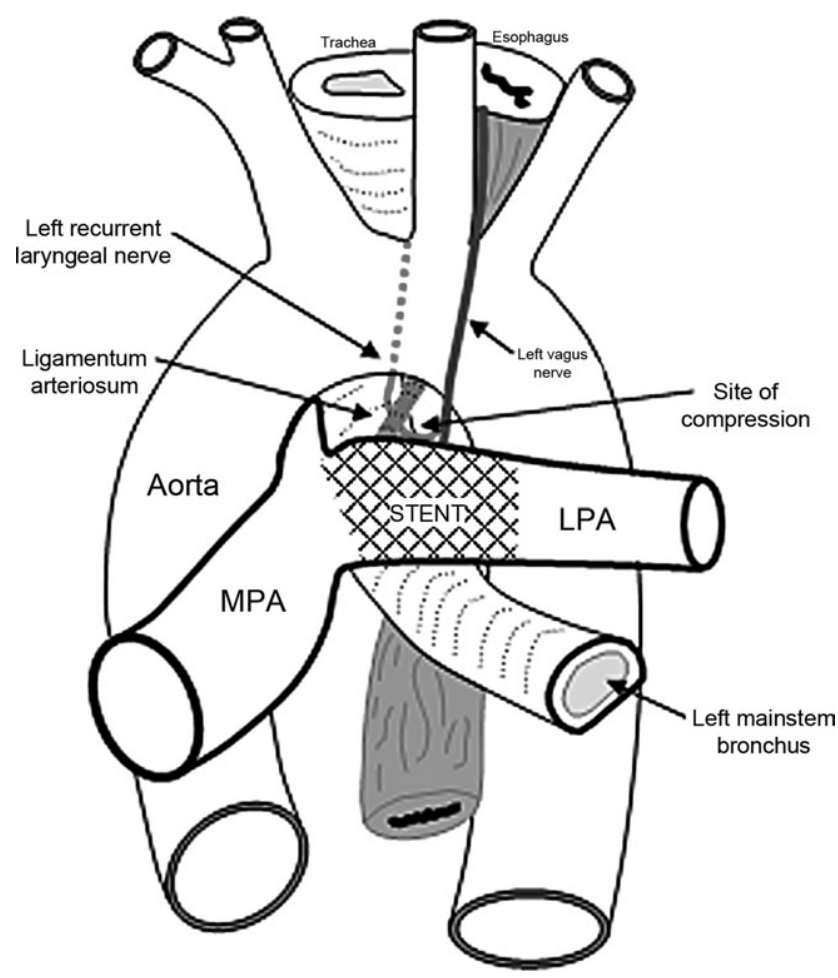

Fig. 3. Anatomical diagram, showing a compression site of left recurrent laryngeal nerve between the left pulmonary artery stent, ligamentum arteriosus and aorta.

relative flow discrepancy between the two lungs of $35 \% / 65 \%$ or worse. The therapeutic window for intervention in branch pulmonary artery stenosis is unknown [7]. However, long-standing stenosis can lead to irreversible distal "low flow" pulmonary artery hypoplasia in the affected segments [7]. A more "normal" pulmonary vascular development can be achieved by early restoration of a more equal pulmonary blood flow distribution [7]. Our patient had flow discrepancy of $20 \% / 80 \%$, considered a class I indication for pulmonary artery stent placement. The distal LPA measured $14 \mathrm{~mm}$ in diameter. The $15 \mathrm{~mm} \times 3 \mathrm{~cm}$ balloon was chosen to obtain sufficient dilation and prevent stent migration. It is difficult to speculate that using a smaller balloon to mount the stent could have prevented this complication.

Left vocal cord paresis after PDA closure and/or LPA stent placement may be transient [2,4]. In our case, left vocal cord dysfunction persisted for 21 months after LPA stent placement, indicating that LRLN paralysis may be a permanent complication. The hoarseness after LPA stent should be evaluated promptly by ENT colleagues. Surgical decompression of the left recurrent laryngeal nerve may be a therapeutic option; however, it could be irreversible even after surgical decompression and the decision should be made based on the severity of hoarseness and patient's quality 
of life. Patients and their family should be informed of this rare complication prior to LPA stent placement.

\section{CONCLUSION}

We report a 10-year-old girl who developed persistent hoarseness after stent placement for the treatment of left pulmonary artery stenosis. Pediatric cardiologists should be reminded of left recurrent laryngeal nerve palsy as a complication of LPA stenting.

\section{REFERENCES}

1. Law MA, Shamszad P, Nugent AW, Justino H, Breinholt JP, Mullins CE, Ing FF. Pulmonary artery stents: Long-term followup. Catheter Cardiovasc Interv 2010;75:757-764.

2. Assaqqat M, Siblini G, Fadley FA. Hoarseness after pulmonary arterial stenting and occlusion of the arterial duct. Cardiol Young 2003;13:302-304.
3. Zbar RI, Chen AH, Behrendt DM, Bell EF, Smith RJ. Incidence of vocal fold paralysis in infants undergoing ligation of patent ductus arteriosus. Ann Thorac Surg 1996;61:814-816.

4. Javois AJ, Patel D, Roberson D, Husayni T. Pre-existing left pulmonary artery stenosis and other anomalies associated with device occlusion of patent ductus arteriosus. Catheter Cardiovasc Interv 2007;70:83-89.

5. Poteliakhoff A, Gottlifeb B. Left recurrent laryngeal nerve paralysis due to dilatation of the pulmonary artery in a case of bronchitis and asthma. Proc R Soc Med 1951;44:410-411.

6. Feltes TF, Bacha E, Beekman RH III, Cheatham JP, Feinstein JA, Gomes AS, Hijazi ZM, Ing FF, de Moor M, Morrow WR, Mullins CE, Taubert KA, Zahn EM; American Heart Association Congenital Cardiac Defects Committee of the Council on Cardiovascular Disease in the Young; Council on Clinical Cardiology; Council on Cardiovascular Radiology and Intervention. Indications for cardiac catheterization and intervention in pediatric cardiac disease: A scientific statement from the American Heart Association. Circulation 2011;123:2607-2652.

7. Bacha EA, Kreutzer J. Comprehensive management of branch pulmonary artery stenosis. J Interv Cardiol 2001;14:367-375. 